\title{
What are the beliefs of pediatricians and dietitians regarding complementary food introduction to prevent allergy?
}

\author{
Sara H Leo ${ }^{1,2^{*}}$, John M Dean ${ }^{1,2}$, Edmond S Chan ${ }^{1,2}$ \\ From Canadian Society of Allergy and Clinical Immunology Annual Scientific Meeting 2011 \\ Quebec, Canada. 20-23 October 2011
}

\section{Background}

Food allergy often manifests on first known oral exposure. Hence, the timing of complementary food introduction is of interest. The American Academy of Pediatrics offers specific dietary guidelines that were updated in 2008.

Objective: We wanted to identify the recommendations that general pediatricians and registered dietitians provide to parents and delineate any differences in counselling.

\section{Methods}

A 9-item survey was distributed to pediatricians and dietitians online and by mail. Information on practitioner type, gender, length of practice and specific recommendations made regarding complementary food introduction and exposure was collected.

\section{Results}

181 surveys were returned with a $54 \%$ response rate from pediatricians. $52.5 \%$ of all respondents were pediatricians and $45.9 \%$ were dietitians. The majority of pediatricians and dietitians advise mothers that peanut abstinence during pregnancy and lactation is unnecessary. Dietitians were more likely to counsel mothers to breastfeed their infants to prevent development of atopic dermatitis than pediatricians. Hydrolyzed formulas for infants at risk of developing allergy were the top choice of formula amongst both practitioners. Pediatricians were more likely to recommend delayed introduction of peanut and egg, while most dietitians recommended no delay in allergenic food introduction to prevent development of food allergy.

'Department of Pediatrics, Division of Allergy, University of British Columbia, Vancouver, British Columbia, Canada, V6H 3V4

Full list of author information is available at the end of the article

\section{Conclusions}

With the exception of whether to recommend breastfeeding to prevent development of atopic dermatitis and whether to delay allergenic food introduction, pediatricians and dietitians agreed closely in their advice and adhered to the 2008 American Academy of Pediatric guidelines. Further education using the latest recommendations should be considered.

\section{Author details}

'Department of Pediatrics, Division of Allergy, University of British Columbia, Vancouver, British Columbia, Canada, V6H 3V4. 'BC Children's Hospital, Vancouver, British Columbia, Canada, V6H 3 V4.

Published: 14 November 2011

doi:10.1186/1710-1492-7-S2-A3

Cite this article as: Leo et al:: What are the beliefs of pediatricians and dietitians regarding complementary food introduction to prevent allergy? Allergy, Asthma \& Clinical Immunology 2011 7(Suppl 2):A3.

Submit your next manuscript to BioMed Central and take full advantage of:

- Convenient online submission

- Thorough peer review

- No space constraints or color figure charges

- Immediate publication on acceptance

- Inclusion in PubMed, CAS, Scopus and Google Scholar

- Research which is freely available for redistribution
C Biomed Central

(ㄷ) 2011 Leo et al; licensee BioMed Central Ltd. This is an open access article distributed under the terms of the Creative Commons Attribution License (http://creativecommons.org/licenses/by/2.0), which permits unrestricted use, distribution, and reproduction in any medium, provided the original work is properly cited. 